patients died, including two treated terminally by I.P.P.V. In a study of five infants with severe bronchiolitis, Downes et al. (1968) showed a striking increase in the dead space to tidal volume ratios and a twofold to threefold increase in minute volume at a $\mathrm{PCO}_{2}$ below $65 \mathrm{~mm} \mathrm{Hg}$. With progressive fatigue the minute volume fell to predicted basal levels and $\mathrm{PCO}_{2}$ rose above $65 \mathrm{~mm} \mathrm{Hg}$. At that stage most infants were severely distressed clinically but recovered after nasotracheal intubation, neuromuscular blockage, and mechanical ventilation.

Our management techniques differ little from those described previously. Though these were important perhaps the major determinant of effective and safe mechanical ventilation was the provision of adequate facilities, the close co-operation of medical, anaesthetic, and laboratory personnel, and continuous skilled nursing. When these conditions are not present the hazards of mechanical ventilation increase sharply.

In recent years there has been an encouraging fall in the number of deaths from pneumonia in our hospital despite an increase in the number of patients admitted with acute lower respiratory tract infection (12-14\% of the total admissions). This is illustrated in fig. 5 , which shows that the number of otherwise normal children dying of bronchiolitis or pneumonia has fallen to 10 in the past six years, compared with 18 and 28 in the preceding two five-year periods. An analysis of the deaths

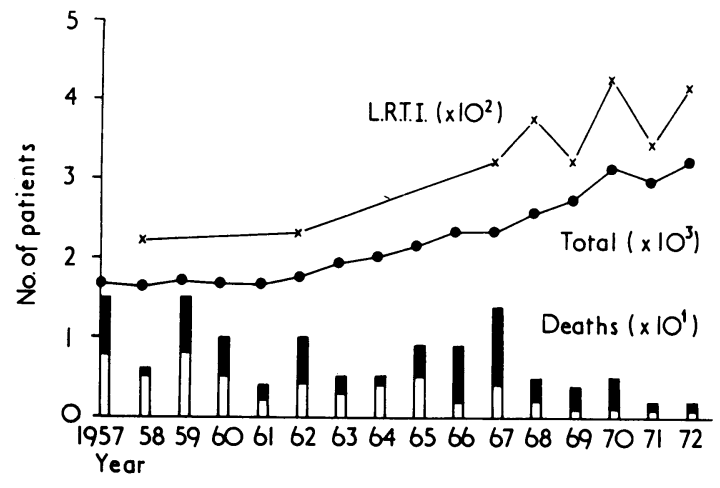

FIG. 5-Acute lower respiratory tract infection (L.R.T.I.). Admissions and deaths in relation to total medical admissions during 1957 to 1972 . Shaded areas represent presence of predisposing cause or congenital abnormality (excludes cystic fibrosis). Open areas represent no predisposing cause or congenital abnormalities present. Age distribution of the 56 patients in whom no predisposing cause or congenital abnormality was present was as follows: $<1$ month, $15 ; 1-6$ months, $33 ; 6$ months to 1 year, $4 ;>1$ year, 4 . Necropsy was performed in 46 . occurring between 1957 and 1966 is given elsewhere (Simpson, 1973). Facilities for blood gas analysis were first available in 1966 but a realistic 24-hour service was not introduced until 1970 , before the opening of the respiratory care unit. Infants with pneumonia represent less than $25 \%$ of those admitted to this unit for treatment of respiratory failure. As it is extremely expensive to provide an optimal service we agree with Downes et al. (1972) that such a service should not necessarily be duplicated in every hospital. Consideration should be given to the distribution of paediatric respiratory intensive care and the safe transportation of patients to such centres.

We wish to thank Professor J. O. Forfar for his support and encouragement, Dr. D. J. Grubb and Dr. R. Burtles for advice and help in ventilating these children, and the physicians at the Royal Hospital for Sick Children, Edinburgh, who referred patients under their care. Our thanks are also due to the nursing staff of the respiratory care unit for their excellent standard of nursing care, and to laboratory staff who provided the blood gas servioe.

\section{References}

Campbell, E. J. M. (1965). British Medical fournal, 1, 1451. Disney, M. E., Sandiford, B. R., Cragg, J., and Wolff, J. (1960). British

Downes, J. J., and Striker, T. W. (1966). Acta Anaesthesiologica Scandinavica, Suppl. no. 23, p. 747.

Downes, J. J., Striker, T. W., Wood, D. W., and Haddad, C. (1968). Anesthesiology, 29, 426.

Downes, J. J., Fulgencio, T., and Raphaely, R. C. (1972). Pediatric Clinics of North America, 19, 423.

Elderkin, F. M., Gardner, P. S., Turk, D. C., and White, A. C., (1965). British Medical fcurnal, 2,722 .

Gardner, P. S., et al. (1967). British Medical fournal, 4, 316.

Heycock, J. B., and Noble, T. C. (1962). British Medical fournal, 2, 879.

Holliday, M. A., and Segar, W. E. (1957). Pediatrics, 19, 823.

Joly, J. B., Huault, G., Amsill, J., Lemerle, J., and Thieffry, S. (1967). Archives Françaises de Pédiatrie, 24, 303.

Jones, R. S., Owen-Thomas, J. B., and Boulton, M. J. (1968). Archives of Disease in Childhood, 43, 415.

Leer, J. A., et al. (1969). American fournal of Diseases of Children, 117, 495. Phelan, P. D., Williams, H. E., Stocks, J. G., and Freeman, M. (1968). Australian Paediatric fournal, 4, 223.

Rees, G. J., and Owen-Thomas, J. B. (1966). British fournal of Anaesthesia, 38,901 .

Reynolds, E. O. R. (1963). Fournal of Pediatrics, 63, 1135.

Simpson, H. (1973). M.D. thesis, University of Edinburgh.

Simpson, H., and Flenley, D. C. (1967). Lancet, $1,7$.

Simpson, H., Matthew, D. J., Inglis, J. M., and George, E. L. (1974). British Medical fournal, 2,629

Stiehm, E. R., and Fudenberg, H. H. (1966). Pediatrics, 37, 715.

Young, J. A., and Crocker, D. (1970). Principles and Practice of Inhalation Therapy. Chicago, Year Book Medical Publishers Inc.

\footnotetext{
McIndoe Research Unit, Queen Victoria Hospital, East Grinstead,

Sussex
HELEN M. CHAPEL, M.B., B.CHIR., Research Assistant (Present address

Department of Experimental Pathology, Medical School, University of Department of Experimental Patholog

Birmingham, Birmingham B15 2TJ)
J. R. BATCHELOR, M.D., Director of Unit.
}

inhibitory concentration of antihuman lymphocyte globulin needed to inhibit rosette formation by $25 \%$ was specifically associated with rejection of such a graft. No such change was observed.

\section{Introduction}

A high proportion of human lymphocytes will react with sheep red blood cells to form spontaneous rosettes (Jondal et al., 1972; Chapel, 1973). This rosette formation has been shown to be inhibited by high dilutions of antihuman lymphocyte globulin (A.L.G.) (Bach et al., 1969), and an in-vitro test based on this inhibition has been described (Munro et al., 1971). It has been suggested that this rosette inhibition test, despite its obscure immunological basis, is a measure of the immunosuppression of 
a patient's lymphocytes (Munro et al., 1971; Cullum et al., 1972; Bewick et al., 1972) and that a change in the minimal inhibitory concentration (M.I.C.) is associated specifically with rejection.

Previous reports on the use of this test have been confined to renal and lung transplant patients. We used the test on skingrafted patients because the date and diagnosis of rejection of a skin graft are definite. These patients had sustained a burn injury on more than $15 \%$ of their total body surface. Skin grafts on such patients often show prolonged survival, presumably associated with depression of cellular immunity (Chambler and Batchelor, 1969; Batchelor and Hackett, 1970), but rejection occurs eventually. If rejection is specifically associated with a change in the rosette inhibition test then this should have been demonstrable at the time that the skin graft underwent rejection.

\section{Patients and Methods}

The details of the rosette inhibition test have been described elsewhere (Chapel and Batchelor, 1973). Briefly, fresh human peripheral blood lymphocytes were prepared from heparinized blood by separation on Ficoll and Triosil (Harris and Ukaejiofo, 1969). The cells were well washed for maximum sensitivity. Aliquots of the lymphocyte suspension in Hank's Balanced Salt Solution were incubated in the serial dilutions of A.L.G. and guinea-pig serum (final dilution $1 / 50$ ). Sheep red blood cells were added after an incubation of 90 minutes at $37^{\circ} \mathrm{C}$. Cells were centrifuged ( $200 \mathrm{~g}$ for 5 minutes), calf serum was added, and the cells were resuspended. The number of rosettes per $10^{3}$ lymphocytes was calculated for each dilution of A.L.G. used after 200 lymphocytes had been examined. The sigmoid curve for each cell suspension was plotted, and the M.I.C. (that concentration of A.L.G. needed to inhibit rosette formation by $25 \%$ ) was calculated.

Five patients who had sustained a burn of greater than $15 \%$ of their total body surface were typed for HL-A, ABO, and rhesus antigens. Skin grafts selected from unrelated typed donors were applied to the patients when grafting became necessary. Grafts were chosen so that they differed from the recipients by at least two $\mathrm{HL}-\mathrm{A}$ antigens. $\mathrm{ABO}$ and rhesus incompatibilities were avoided in all cases. Skin was obtained routinely from cadavers within 16 hours of death. Strips $(10 \times$ $20 \mathrm{~cm}$ ) were sealed in polyethylene bags, frozen at a controlled rate, and stored until needed in a viable state (Cochrane, 1968). Blood was taken from the cadavers at the same time and tested for HL-A, ABO, and rhesus antigens. The grafting was done by the plastic surgeons in charge of the burns centre; the details have been described previously (Batchelor and Hackett, 1970). All the grafts were viable after grafting and rejection was read macroscopically. The areas of the grafts ranged from 35-170 $\mathrm{cm}^{2}$

\section{Results}

The rosette inhibition test is very reproducible. We have shown that the standard deviation for a given cell suspension is $7 \%$. The normal mean value, obtained by testing a single A.L.G. in the cells of 41 normal individuals, is $1 / 22,000$ (S.D. $=1 / 6,000$ ) (Chapel and Batchelor, 1973).

Serial tests on the five patients investigated are shown in the table. Cases 1,3 , and 5 clearly show that there was no significant change in the M.I.C. on the day that the patients skin grafts were rejected. Cases 3, 4, and 5 show extended graft survival times. Cepellini et al. (1966) found a mean survival time of $12 \cdot 1$ days (range 9-16) for 42 ABO-compatible, but otherwise randomly chosen, full-thickness grafts placed on unburned recipients. The survival times of 21,47 , and 17 days in cases 3,4 , and 5 respectively were extended by comparison, using similar criteria for rejection. These patients, whose immune responses were suppressed, showed a normal M.I.C. on or about the time of grafting and in two patients (cases 3 and 5) there was no change in M.I.C. throughout the grafted period, despite prolonged graft survival. In case 4 a change was seen on the 11th day after grafting, but the cells on that day needed more A.L.G. rather than less for inhibition of rosette formation. This showed that immunosuppression, as measured by survival of the graft, was not reflected by an abnormal M.I.C.

Previous studies (Batchelor and Hackett, 1970) have shown that grafts on patients with an area of burn of greater than $18 \%$ of their total body surface have prolonged survival. The extent of prolongation is related to the area of burn (Chambler and Batchelor, 1969). Two of our patients (cases 1 and 2) did not show prolonged graft survival; an area of burn of the $15 \%$ of the total body surface may be the critical size for showing such extended survival.

Results of Serial Tests in Five Skin-grafted Patients

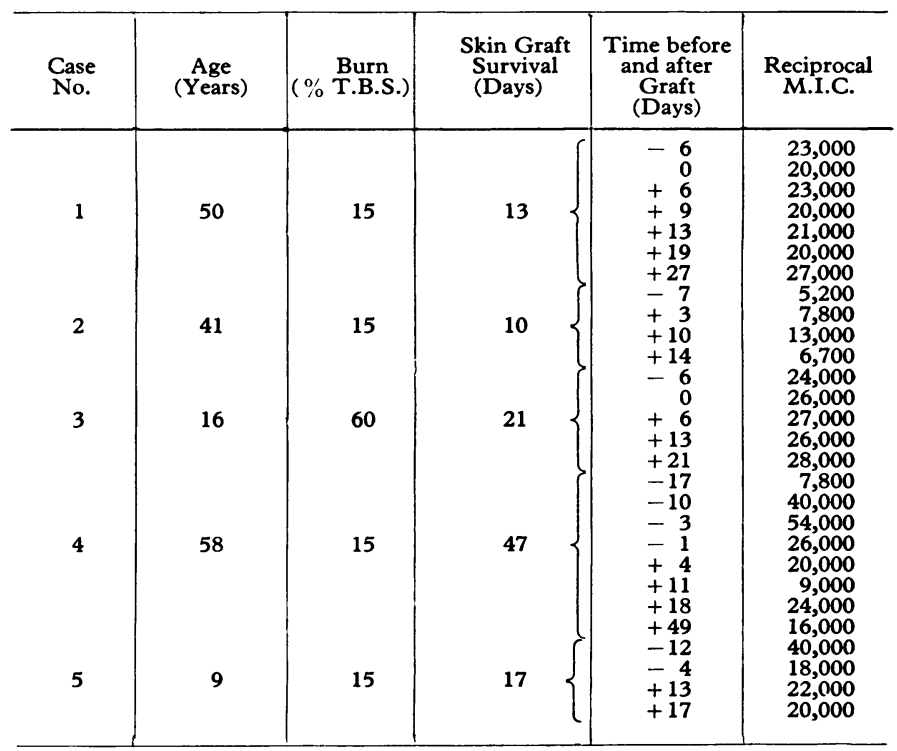

T.B.S. = Total body surface.

\section{Discussion}

It has been suggested that the M.I.C. measures the immune reactivity of an individual (Munro et al., 1971; Cullum et al., 1972; Bewick et al., 1972). If a small amount of A.L.G.- that is, a high dilution-inhibits rosette formation by an arbitrary figure-conventionally $25 \%$-it has been postulated that the lymphocyte donor is immunosuppressed. In contrast, normal immunological reactivity is claimed to be present when the amount of A.L.G. needed for rosette inhibition is the same as that needed for the cells of normal people. It was claimed that a change in M.I.C. (from a high to a lower dilution of A.L.G.) accompanied rejection specifically.

We have shown that prolonged survival of a skin graft was not associated with an abnormal M.I.C. The rejection of a skin graft was also not accompanied by a significant change in M.I.C. in any of the five patients studied. It may be that rejection of skin is not a sufficiently major process to cause a change in M.I.C. whereas rejection of an internal organ is a more severe reaction, and this may account for the changes in M.I.C. which accompany renal rejection since major pathological processes have been shown to correlate with changes in M.I.C. (Chapel and Batchelor, 1973).

We thank the surgical and nursing staff of the McIndoe Burns Unit for their help in treating and grafting these patients and Miss Linda Daley for her excellent technical help. We also thank the East Grinstead Research Trust and the Medical Research Council for their financial support. 


\section{References}

Bach, J. F., Dardenne, M., Dormant, J., and Antoine, B. (1969). Transplantation Proceedings, 1, 403.

Batchelor, J. R., and Hackett, M. (1970). Lancet, 2, 581.

Bewick, M., Ogg, C. S., Parsons, V., Snowdon, S. A., and Manuel, L. (1972). British Medical Fournal, 3, 491.

Cepellini, R., Curtoni, E. S., Mattiuz, P. L., Leigheb, G., Visetti, M., and

Colombi, A. (1966). Annals of the New York Academy of Sciences, 129, Colom.
Chambler, K., and Batchelor, J. R. (1969). Lancet, 1, 16.

Chapel, H. M. (1973). Transplantation, 15, 320

Chapel, H. M., and Batchelor, J. R. (1973). British Medical fournal, 4, 385.

Cochrane, T. (1968). British fournal of Plastic Surgery, 21, 118.

Cullum, P. A., et al. (1972). British Medical Fournal, 2, 7

Harris, R., and Ukaejiofo, E. O. (1969). Lancet, 2, 327

Jondal, M., Holm, G., and Wigzell, H. (1972). Fournal of Experimental Medicine, 136, 207.

Munro, A., et al. (1971). British Medical fournal, 3, 271

\title{
Testicular Pain Sensation in Diabetic Autonomic Neuropathy
}

\author{
I. W. CAMPBELL, \\ D. J. EWING, \\ B. F. CLARKE, \\ L. J. P. DUNCAN
}

British Medical fournal, 1974, 2, 638-639

\begin{abstract}
Summary
Testicular sensation was examined in 32 male diabetics with symptoms suggestive of autonomic neuropathy to evaluate its usefulness as a clinical sign in this condition. Vascular reflex responses to the Valsalva manoeuvre and sustained handgrip and blood pressure fall on standing were measured as objective tests of autonomic involvement. Absent or diminished testicular sensation correlated well both with the clinical features of autonomic neuropathy, except where impotence occurred alone, and with abnormal vascular reflexes. Most patients with impotence alone had normal testicular sensation and normal vascular reflexes. It is concluded that this sign is useful in diabetics with impotence, the presence of intact testicular sensation indicating that the impotence is unlikely to be due to autonomic neuropathy.
\end{abstract}

\section{Introduction}

Though clinical features, in retrospect attributable to autonomic nerve involvement, were described by Auché (1890) and Pryce (1893) in diabetes mellitus it was Rundles (1945) who first clearly delineated the characteristic symptom complexes of autonomic neuropathy. Pitres (1902) reported impairment of deep testicular pain sensation in four diabetics. Nevertheless, this sign has been largely ignored and we have not found any further reference to it in the literature. In the experience of one of us (L.J.P.D.), however, demonstrable impairment or absence of testicular pain sensation is often found in male diabetics with autonomic neuropathy. For this reason a group of diabetics with autonomic neuropathy were studied to assess the possible usefulness of this sign.

\section{Patients and Methods}

Thirty-two male diabetics with characteristic clinical features of autonomic neuropathy (Keen, 1959; Colby, 1965) were

Diabetic and Dietetic Department, Royal Infirmary, Edinburgh EH3 9YW

I. W. CAMPBELL, M.B., M.R.C.P., Registrar in Medicine

B. F. CLARKE, M.B., F.R.C.P., Consultant Physician

B. F. CLARKE, M.B., F.R.C.P., Consultant Physician

University Department of Medicine, Royal Infirmary, Edinburgh nH3 9YW

D. J. EWING, M.B., M.R.C.P., Lecturer in Medicine studied. The most common symptom was persistent impotence; in 14 patients it was the only symptom suggestive of autonomic neuropathy, in another 17 it was accompanied by other features of the condition, and only one patient denied impotence. Other symptoms included postural hypotension (eight patients), intermittent nocturnal diarrhoea (nine patients), gastric fullness or delay in emptying (four patients), hypoglycaemic unawareness (six patients), and diminished sweating in the lower extremeties (one patient). In addition 23 patients had clinical features of peripheral neuropathy, 23 had diabetic retinopathy, and 12 had persistent proteinuria. Their mean age was 48 years (range 24-63 years), and the average duration of diabetes was 17 years (range 2-33). All except four were dependent on insulin.

Deep testicular pain sensation was determined by holding the subject's scrotum in one hand and firmly squeezing each testicle in turn between the thumb and first two fingers of the other hand, increasing the pressure until pain was felt. The response was considered normal if the patient started to experience a peculiar "sickening" pain on moderate pressure (Bailey and Clain, 1954), diminished if considerable pressure elicited only unpleasant but tolerable discomfort, and absent if full pressure evoked no response whatsoever. Pain appreciation on squeezing the tendo Achillis was tested as another measure of deep pain sensation.

In all patients an independent observer measured vascular reflex responses as an objective assessment of autonomic neuropathy. The Valsalva manoeuvre and the response to sustained handgrip at $30 \%$ maximum voluntary contraction were defined as normal or abnormal as previously described (Ewing et al., 1973). A fall of systolic blood pressure of $30 \mathrm{~mm} \mathrm{Hg}$ or greater immediately on changing from the lying to standing position was taken to indicate postural hypotension.

\section{Results}

Twelve patients had absent, six had diminished, and 14 had normal testicular sensation. When these results were related to the presence or absence of other clinical features and objective assessment of autonomic neuropathy striking differences were observed.

TESTICULAR SENSATION AND CLINICAL FEATURES OF AUTONOMIC NEUROPATHY

Of the 14 patients with impotence alone only two had reduced testicular sensation whereas of the 18 patients with other features 11 had absent and five had diminished testicular sensation (table I). The one man without impotence had normal testicular sensation. There were no statistical differences in age or duration of diabetes between the two groups. 